\title{
Antihypertensive combination therapy in primary care offices: results of a cross-sectional survey in Switzerland
}

\author{
Susanne Roas' \\ Felix Bernhart ${ }^{2}$ \\ Michael Schwarz ${ }^{3}$ \\ Walter Kaiser ${ }^{4}$ \\ Georg Noll ${ }^{5}$
}

'Department of Internal Medicine, University Hospital, Zurich, ${ }^{2}$ Private Practice, Biberist, ${ }^{3}$ Ambulatorium Wiesendamm, Basel, ${ }^{4} \mathrm{Healthworld}$ (Schweiz) AG, Steinhausen, ${ }^{5}$ HerzKlinik Hirslanden, Zurich, Switzerland
This article was published in the following Dove Press journal:

International Journal of General Medicine

9 December 2014

Number of times this article has been viewed

Background: Most hypertensive patients need more than one substance to reach their target blood pressure (BP). Several clinical studies indicate the high efficacy of antihypertensive combinations, and recent guidelines recommend them in some situations even as initial therapies. In general practice they seem widespread, but only limited data are available on their effectiveness under the conditions of everyday life. The objectives of this survey among Swiss primary care physicians treating hypertensive patients were: to know the frequency of application of different treatment modalities (monotherapies, free individual combinations, single-pill combinations); to see whether there are relationships between prescribed treatment modalities and patient characteristics, especially age, treatment duration, and comorbidities; and to determine the response rate (percentage of patients reaching target BP) of different treatment modalities under the conditions of daily practice.

Methods: This cross-sectional, observational survey among 228 randomly chosen Swiss primary care physicians analyzed data for 3,888 consecutive hypertensive patients collected at one single consultation.

Results: In this survey, $31.9 \%$ of patients received monotherapy, $41.2 \%$ two substances, $20.9 \%$ three substances, and $4.7 \%$ more than three substances. By combination mode, $34.9 \%$ took free individual combinations and $30.0 \%$ took fixed-dose single-pill combinations. Combinations were more frequently given to older patients with a long history of hypertension and/or comorbidities. In total, $67.8 \%$ of patients achieved their BP target according to their physician's judgment. When compared, single-pill combinations were associated with a higher percentage of patients achieving target BP than free individual combinations and monotherapies for the total sample and for patients with comorbidity.

Conclusion: Antihypertensive combination therapy was widely used in Swiss primary care practices. The number of prescribed substances depended on age, treatment duration, and type and number of comorbidities. Although the response rate was generally modest under the conditions of daily practice, it was higher for single-pill combinations than for monotherapies and free individual combinations. Further studies are needed to confirm these observations.

Keywords: hypertension, combination therapy, comorbidity, single-pill combination, fixeddose combination

\section{Introduction}

In hypertension management, monotherapies (MT) are often insufficient for patients to achieve target blood pressure (BP); in many cases, more than one substance class is needed to reach goal BP. ${ }^{1-3}$ Several clinical studies indicate the high efficacy of combined antihypertensive therapy, as reviewed by de la Sierra et al. ${ }^{4}$ It was also reported that combining any two classes of antihypertensive agents in low
Correspondence: Georg Noll HerzKlinik Hirslanden, Witellikerstrasse 40, CH 8032 Zurich, Switzerland

$\mathrm{Tel}+4$ I 443879700

Fax +4I 443879710

Email georg.noll@hirslanden.ch 
doses reduces BP to a greater extent than uptitrating any monotherapy to maximum dose..$^{5}$ Recent guidelines recommend combination therapy even as initial therapy if BP is $>20 \mathrm{mmHg} / 10 \mathrm{mmHg}$ above target. ${ }^{3,6-8}$ Some advantageous substance combinations are available as single-pill combinations (SPC), which simplify treatment schemes and increase compliance as compared with free individual pill combinations (FIC). ${ }^{9-11}$ In clinical trials and cohort studies, SPC of antihypertensive agents are associated with a significant improvement in compliance and with nonsignificant beneficial trends in BP and adverse effects as compared with the same substances given as individual pills. ${ }^{11}$ In general practice, SPC seem to be broadly used nowadays, ${ }^{12-14}$ and some reports describe a higher likelihood of successful BP control when substances are given as SPC instead of FIC. ${ }^{15}$ This suggests that the superior efficacy of SPC documented in controlled clinical trials ${ }^{16}$ may translate into improved BP control in daily practice.

The objectives of this observational survey among Swiss primary care physicians caring for hypertensive patients were: to know the frequency of use of different treatment modalities (MT, FIC, SPC); to see whether there are relationships between patient characteristics, especially age, treatment duration, and comorbidities, and prescribed antihypertensive treatment modalities; and to determine the response rate (percentage of patients reaching target $\mathrm{BP}$ ) for different treatment modalities in various subgroups under the conditions of daily practice.

\section{Materials and methods Survey design}

This was a cross-sectional survey among 228 Swiss primary care physicians to collect demographic and disease-related data about hypertensive patients at one single consultation in the primary care office.

\section{Patients}

Primary care physicians in Switzerland were randomly chosen and contacted by letter to take part in this survey. Between December 2012 and March 2013, 228 Swiss general practice physicians participated, and contributed a total of 3,888 hypertensive patients. Each physician was requested to record within a freely selectable period of 2 weeks the first (up to) 20 consecutive patients consulting them because of hypertension or diabetes (only when associated with hypertension). Inclusion occurred irrespective of patient profile and of whether and how the patient was treated. Patients were informed about the survey and gave verbal consent.
The survey as a noninterventional study so did not require approval by an ethics committee.

\section{Data}

For each patient, the following data were recorded by the participating physicians using individual patient forms: demographic characteristics, BP reading at consultation, current antihypertensive treatment, achievement of BP goals (generally $<140 / 90 \mathrm{mmHg}$, but $<130 / 80 \mathrm{mmHg}$ for patients suffering from diabetes mellitus or renal insufficiency) ${ }^{6}$ according to office $\mathrm{BP}$ reading (method of measurement according to usual practice standards, which mostly involve automated measurement) and evaluation by the physician (who judged the reading in light of the patient's history, especially former office or home measurements), comorbidities, duration of antihypertensive treatment, and possible modifications of antihypertensive therapy at consultation.

Comorbidities were recorded in broad, predefined categories (diabetes, dyslipidemia, heart disease, renal insufficiency, other), without further specification, in order to avoid subgroups with insufficient patient numbers for statistical analysis. The diagnoses of comorbidities were made by physicians according to their usual practice standards.

\section{Statistical analysis}

Continuous variables are expressed as the mean \pm standard deviation and categorical variables are expressed as the relative frequency. Descriptive statistics were performed using Excel 2010 (Microsoft Corporation, Redmond, WA, USA). The categorical, dichotomous outcome variable of BP goal attainment as judged by the attending physician was compared using the $\chi^{2}$ test of association (four-square test) as a function of the therapeutic modality both for the entire population and for subgroups with comorbidities. Possible differences between various subgroups regarding continuous variables, such as demographic characteristics, number of substances taken, and therapeutic modalities used, were analyzed with a one-sided or two-sided Student's $t$-test. For all statistical tests performed, differences between groups were considered statistically significant if $P<0.05$; missing values or nonspecified variables were excluded from the respective analyses.

\section{Results}

\section{Patient characteristics}

Of the 3,888 patients, 1,941 (49.9\%) were males and 1,841 $(46.7 \%)$ were females, with the remainder having no indication of sex in their records. The mean patient age was 
$68.7 \pm 12.0$ years. Comorbidities were found in $75.6 \%$ of patients, the most frequent being dyslipidemia (41.0\%), heart disease $(31.6 \%)$, diabetes mellitus $(29.1 \%)$, and renal insufficiency $(9.5 \%)$, with $18.1 \%$ suffering from diabetes and dyslipidemia. Duration of antihypertensive therapy was longer than 10 years in $1,663(42.8 \%)$ patients, 5-10 years in $981(25.2 \%), 1-5$ years in $859(22.1 \%)$, less than 1 year in $327(8.4 \%)$, and not indicated for 58 patients $(1.5 \%)$.

\section{Application of treatment modalities}

At consultation, $31.9 \%$ of patients received MT, $41.2 \%$ received two substances, $20.9 \%$ received three substances, and $4.7 \%$ received more than three substances, with therapy not specified (not indicated) for $1.3 \%$. Among the $66.8 \%$ of patients receiving combination therapies, $34.9 \%$ received FIC and $30.0 \%$ SPC, with the combination modality not specified in $2.0 \%$.

The number of prescribed substances was associated with patient age, duration of treatment, and number of comorbidities. The number of prescribed substances increased with patient age; patients receiving monotherapy were of mean age $65.6 \pm 12.7$ years, those with two substances were aged $69.1 \pm 11.5$ years, those with three substances were aged $71.6 \pm 10.8$ years, and those with more than substances were aged $71.4 \pm 11.0$ years. The increase in patient age was significant for each added substance up to three substances $(P<0.0001)$.

The percentage of patients receiving combination therapies increased with treatment duration; $66.8 \%$ of patients treated for less than 1 year took MT, while $77.3 \%$ treated for longer than 10 years received a combination of therapies $(P<0.0001)$.

Patients without comorbidities ingested MT in 51.4\% of cases, two substances in $36.3 \%$, and three substances in $10.4 \%$; patients without comorbidities did not receive more than three substances and therapy was not specified in 1.9\%. Among comorbid patients, only $26.1 \%$ took MT, $43.0 \%$ received two substances, $24.2 \%$ received three substances, $5.9 \%$ received more than three substances, and therapy was not specified in $8 \%$ (Figure 1). On average, patients without comorbidity ingested $1.61 \pm 0.71$ antihypertensive substances, while patients with at least one comorbidity received $2.10 \pm 0.86$ substances $(\Delta=0.49$ substances, $P<0.0001$; see Figure 1 for a more detailed subgroup analysis).

\section{Composition of antihypertensive combinations}

SPC with two substances mostly combined an angiotensin receptor blocker $(\mathrm{ARB})$ or an angiotensin-converting enzyme inhibitor (ACE-I) with either a diuretic or a calcium antagonist. FIC with two substances mostly had the same composition or combined an ARB or an ACE-I with a betablocker. FIC with three substances contained mostly either an ARB or an ACE-I plus a diuretic and a beta-blocker plus a diuretic and a calcium antagonist. The only available SPC comprising three substances was an ARB plus a diuretic and a calcium antagonist (see Table 1 for a detailed overview).

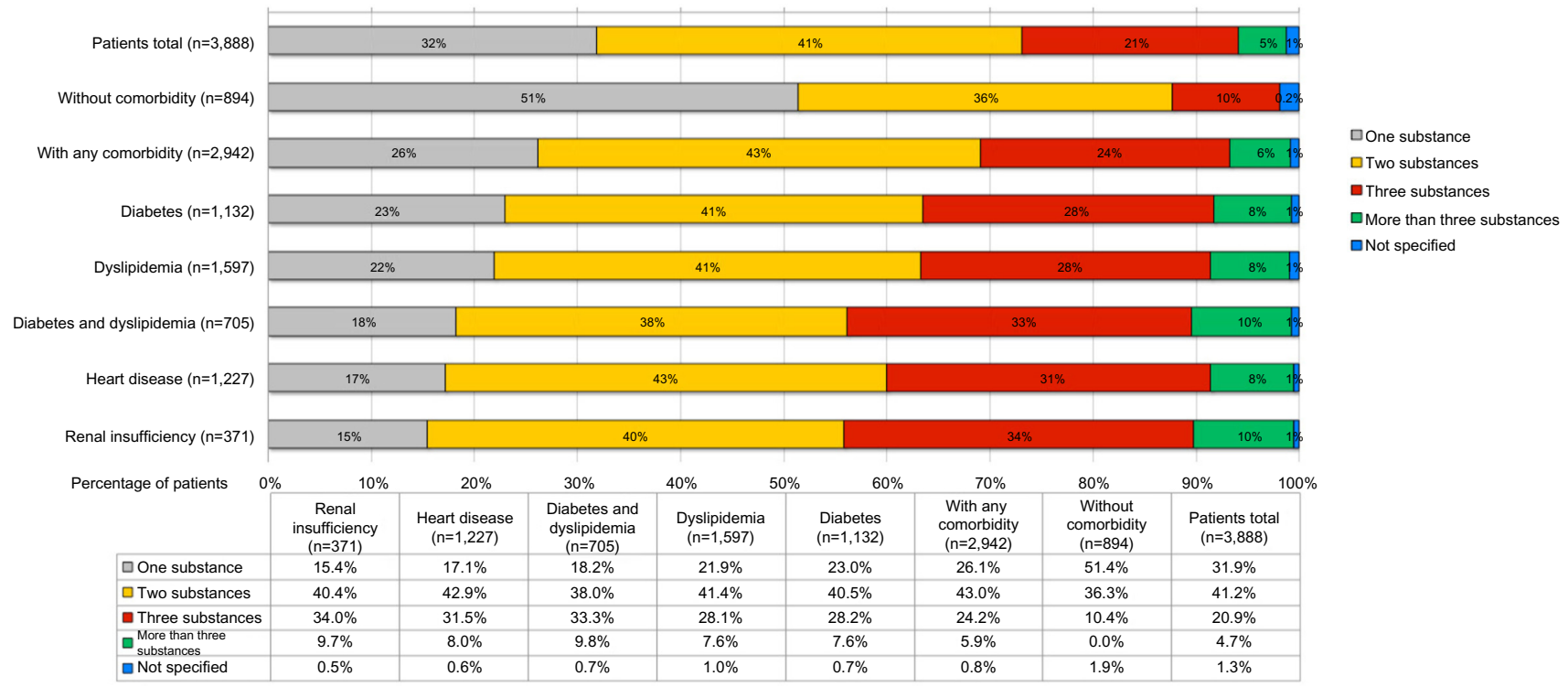

Figure I Percentage of patients receiving antihypertensive combination therapy increases with comorbidities. The number of substances taken by patients is plotted as a function of comorbidities. 
Table I Usage of antihypertensive substances in Swiss primary care offices. The percentage of patients receiving given substance(s) and the respective combination mode (individual or single-pill) is indicated as percentage of the total population. Note that only combinations prescribed to more than 50 patients are shown

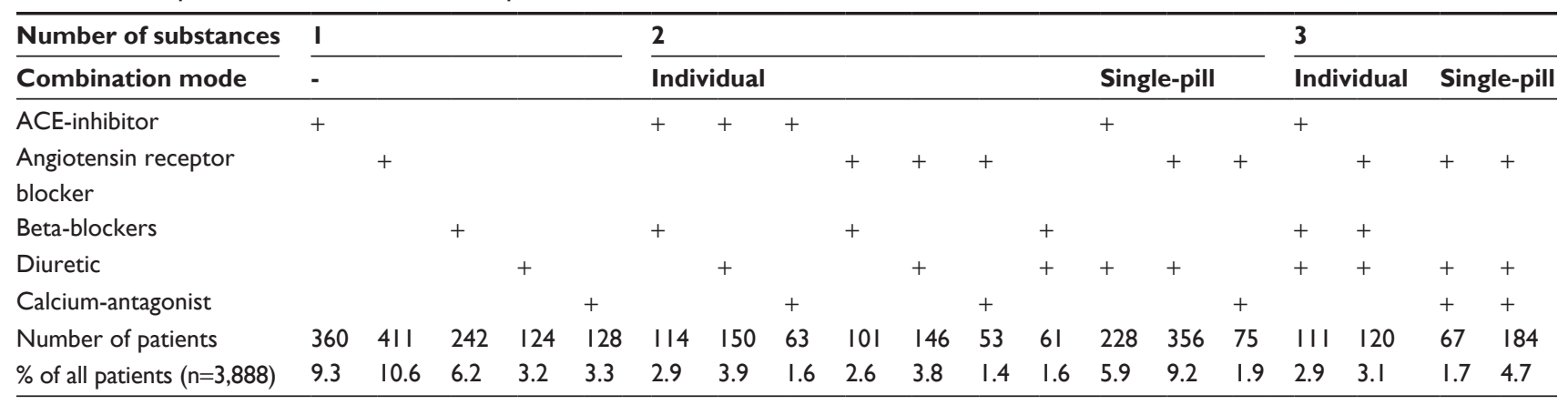

Abbreviation: ACE, angiotensin-converting enzyme.

\section{General results for antihypertensive treatment}

The mean BP value at consultation was $137.5 \mathrm{mmHg}$ / $81.8 \mathrm{mmHg}$, with $55.3 \%$ of all patients achieving their target values as per office BP reading. According to the judgment of their attending physicians, who considered mainly the patient's history as additional information, $67.8 \%$ reached their target BP. The physicians planned a change of therapy in $20.8 \%$ of their patients.

\section{Results for different treatment modalities}

In the total sample, patients receiving SPC reached target values more often than those who took FIC ( $72.6 \%$ versus $68.0 \%$, $\Delta=4.6 \%, P=0.013)$ or MT $(72.6 \%$ versus $68.2 \%, \Delta=4.4 \%$,
$P=0.020$; see Figure 2). Also, in the comorbid patient group overall, SPC were associated with a higher degree of BP control (SPC versus FIC, $71.8 \%$ versus $67.4 \%, \Delta=4.4 \%, P=0.030$; SPC versus MT, $71.8 \%$ versus $66.6 \%, \Delta=5.2 \%, P=0.022$; see Figure 2), as well as in patients suffering from either diabetes (SPC versus FIC, $64.4 \%$ versus $57.4 \%, \Delta=7.0 \%, P=0.037$; SPC versus MT, $64.4 \%$ versus $54.2 \%, \Delta=10.2 \%, P=0.010$; see Figure 2) or dyslipidemia (SPC versus FIC, $72.0 \%$ versus $66.1 \%, \Delta=5.9 \%, P=0.028$; $\mathrm{SPC}$ versus $\mathrm{MT}, 72.0 \%$ versus $64.6 \%, \Delta=7.4 \%, P=0.021$; see Figure 2). Similar outcome comparisons for hypertensive patients suffering from heart disease, renal insufficiency, or diabetes plus dyslipidemia also showed beneficial BP trends when receiving SPC, but these did not reach statistical significance (data not shown).

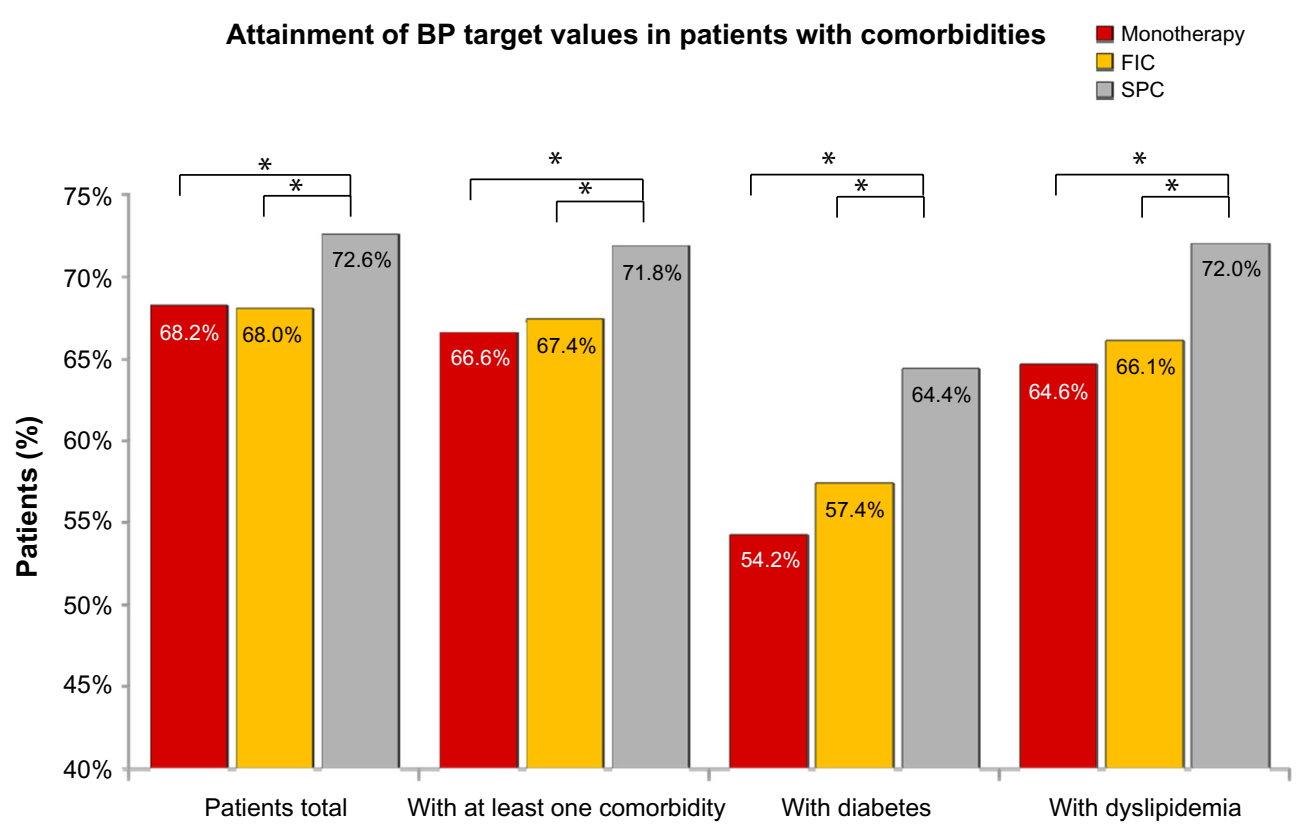

Figure 2 Antihypertensive SPC are associated with higher effectivity than FIC and monotherapy.

Notes: The percentage of patients attaining their individual BP targets is shown for the whole population and the subgroups of all comorbid patients as well as patients suffering from either diabetes or dyslipidemia. $* P<0.05$.

Abbreviations: BP, blood pressure; FIC, free individual combinations; SPC, single-pill combinations. 
When we analyzed BP control irrespective of combination mode (MT, FIC, SPC) and solely as a function of the number of substances taken, we found that in the total sample as well as in most subgroups that patients receiving two substances had the best BP control.

\section{Results for different SPC}

SPC with two substances usually contained an ACE-I or an $\mathrm{ARB}$ and a diuretic or consisted of an ARB combined with a calcium antagonist, while an ACE-I was rarely combined with a calcium antagonist (Table 1). We compared rates of target BP attainment for these four combinations in patients with and without comorbidities. In the total sample, as well as in the subgroups of all comorbid patients and in patients suffering from diabetes or dyslipidemia, SPC consisting of $\mathrm{ARB}$ and a calcium antagonist were associated with a higher percentage of patients reaching target $\mathrm{BP}$ as compared with the three combinations of ARB/diuretic, ACE-I/diuretic, and ACE-I/calcium antagonist (for details, see Figure 3).

\section{Discussion}

\section{Patients}

The average patient age (68.7 \pm 12.0 years) and sex distribution in this survey conformed to Swiss hypertension prevalence data. ${ }^{17}$ The overall comorbidity rate of $76 \%$ aligned with epidemiological surveys, where at least two thirds of hypertensive patients suffered from comorbidities. ${ }^{18,19}$ The prevalence of specific comorbidities such as diabetes and dyslipidemia was comparable with that of a larger survey in a Western population. ${ }^{20}$ Therefore, our data may be considered representative for Switzerland with regard to demographics and as typical with regard to comorbidities in hypertensive patients.

\section{Usage of treatment modalities}

Treatment of arterial hypertension with combination therapy was widely used in Swiss primary care. While only one third of patients took MT, two thirds received more than one substance and one fifth received three or more antihypertensive agents. This is in accordance with other papers reporting that about three quarters of hypertensive patients require more than one substance for BP control, ${ }^{1,3}$ and one third need three substances. ${ }^{7,21}$

In our sample, patients who were older, those who had a longer duration of hypertension, and those who suffered from comorbidities received more antihypertensive substances than younger patients with a shorter history of hypertension and without comorbidities. This may reflect the natural course

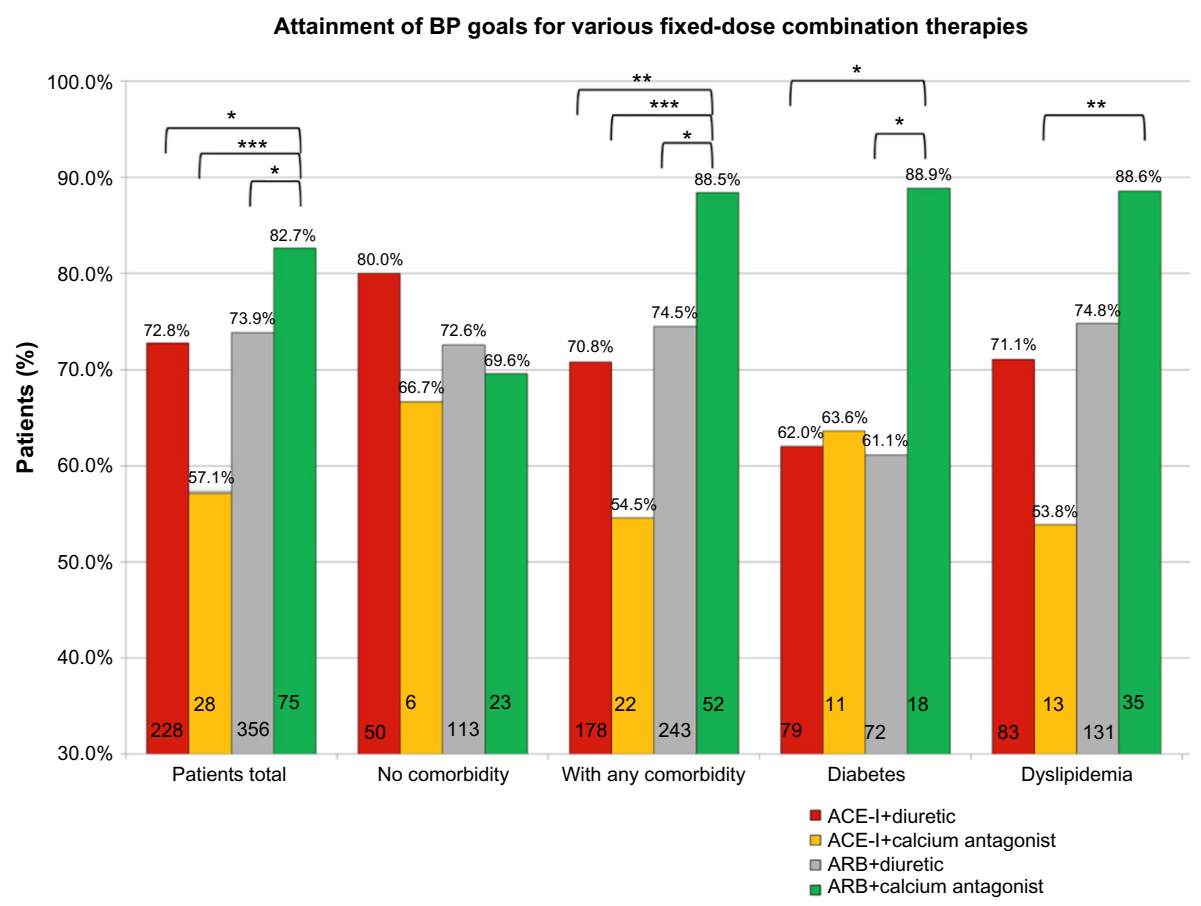

Figure 3 Single-pill combinations of two substances comprised of an ARB and a calcium antagonist are associated with higher effectivity than other such combinations in the whole population and certain comorbidity subgroups. The percentage of patients attaining their individual BP targets is shown for the general population and the subgroups of comorbid patients as well as patients suffering from either diabetes or dyslipidemia. The numbers inside the columns are absolute patient numbers. $* P<0.05$; $* * P<0.0$; $* * * P<0.001$.

Abbreviations: ACE-I, angiotensin-converting enzyme inhibitor; ARB, angiotensin receptor blocker; BP, blood pressure. 
of hypertension, which might become more severe over time. Comorbidities may also be the consequence of the same risk factors as hypertension itself (obesity favors hypertension, diabetes, and dyslipidemia) or of hypertensive complications (heart disease, renal failure).

In this survey, among all patients receiving combinations, about half of them took FIC (34.9\% of total) and the other half took SPC (30.0\% of total). When combination therapy is indicated, recent guidelines recommend SPC. ${ }^{3}$ The earlier criticism that SPC are not flexible enough for individual dosing is nowadays invalidated, given that the individual components of these products are usually available in a broad dosage range. ${ }^{3}$ Improved compliance under SPC was shown for Switzerland ${ }^{13}$ and other countries, ${ }^{22}$ which can be explained by the more simple treatment schemes. ${ }^{9-11,23}$ Thanks to better compliance, SPC may contribute to better BP control and clinical outcomes. In a recent study, the incidence of cardiovascular events was reduced by more than one quarter in patients receiving SPC as compared with patients taking FIC, ${ }^{24}$ suggesting that elevated compliance may translate into measurable improvements in hard cardiovascular endpoints. SPC may also decrease the costs for BP management as shown in Swiss and German primary care. ${ }^{12,13}$

\section{General response rate to antihypertensive treatment}

In the population of 3,888 patients, only $55.3 \%$ were on target according to BP readings as measured at consultation, while $67.8 \%$ were on target according to their physician's judgment. As a single BP reading does not necessarily reflect the patient's average or usual BP value, the attending physician had to judge the measured value. It may be assumed that he/she compared it with home or former office measurements and thus considered the patient's long-term BP development and life circumstances. Physicians made their judgments according to their usual practice standards, as the survey did not dictate a certain procedure for judgment of BP.

The observed discrepancy between measured values and the physician's judgment may be explained in great part by white coat hypertension, which affects a quarter of patients. ${ }^{25}$ Moreover, the survey did not demand a certain method of measurement (manual or automated) and likely included manual BP readings, which are generally biased toward higher values as compared with automated readings. ${ }^{26}$

Even if the higher degree of BP control as judged by attending physicians was taken into account as a measure for therapy outcome, the overall response rate seemed moderate. However, this is in line with larger epidemiologic studies showing that BP goal attainment rates are generally low in Switzerland and other countries. ${ }^{2,20,27}$ Often only half of all treated patients reached target values..$^{2,14,28-30}$

\section{Results by treatment modalities}

In this survey, SPC were associated with a higher percentage of patients reaching target BP than FIC or MT for the total patient sample as well as for comorbid patients suffering from diabetes or dyslipidemia. This is in accordance with recent reports ${ }^{15,20}$ describing greater effectiveness for SPC than for FIC and MT. Several reviews and guidelines recommend SPC if more than one substance is needed to control hypertension or even as initial first-line therapy with low starting doses, ${ }^{3,27,31}$ especially in comorbid patients, in whom BP control is notoriously difficult. ${ }^{32,33}$

\section{Advantages and disadvantages of individual substances used in combination therapy}

Among the frequently used SPC with two substances, ie, ACE-I/diuretic, ACE-I/calcium antagonist, ARB/diuretic, and $\mathrm{ARB} /$ calcium antagonist, the $\mathrm{ARB} /$ calcium antagonist combination was associated with the greatest effectiveness in the total population and in comorbid patients (for details, see Figure 3). Although commonly used substances yield similar BP reductions when used as monotherapy, ${ }^{5}$ some substance combinations might be more effective than others and/or better compensate each other's adverse effects.

In most clinical trials examining the cardiovascular outcome of drug combinations, treatment started with MT and further drugs were added according to different criteria. There were no major outcome differences between different combinations, with a few exceptions. ${ }^{3}$ In two studies, $\mathrm{ARB} /$ diuretic and ACE-I/calcium antagonist combinations respectively reduced cardiovascular events more than a betablocker/diuretic combination. ${ }^{34,35}$ Only one single large trial directly compared calcium antagonists with diuretics headto-head when either was combined with an ACE-I and found superiority of calcium antagonism over diuretics in terms of stroke reduction, despite no observed BP difference. ${ }^{36}$ However, in certain patient groups, such as diabetics, calcium antagonists seem the preferable combination partner for a renin-angiotensin system inhibitor for medical reasons, as diuretics may worsen symptoms of diabetes and/or increase cardiovascular risk. ${ }^{37,38}$ 


\section{Limitations}

This survey had an observational design and analyzed data from one single physician's consultation under nonstandardized conditions. Due to the large number of hypertensive patients included, who showed the typical characteristics of this population, the results give a reliable description of antihypertensive treatment and its outcome in primary care in Switzerland. Nevertheless, the survey cannot explain the reasons for the results, eg, why combination therapy was more effective when administered as a single-pill versus several pills. Besides better compliance, there might be confounding factors beyond our control, such as different patient populations. Therefore, our results are hypothesisgenerating, but cannot be regarded as providing conclusive evidence and thus should be interpreted with caution. Further studies are needed to confirm our results.

\section{Conclusion}

In this study, antihypertensive treatment comprising combinations of substances is widely used in primary care practices in Switzerland. The number of antihypertensive substances given to patients was associated with patient age, duration of treatment of hypertension, and comorbidities. The response rate as a percentage of patients reaching target $\mathrm{BP}$ was generally moderate. However, in this respect, SPC were associated with a higher percentage of patients reaching target BP than were FIC and MT in the general practice setting.

\section{Disclosure}

This survey was supported by an unrestricted grant from Novartis Pharma Schweiz AG. The sponsor was not involved in and had no influence on the drafting of the manuscript. The authors bear full responsibility for the content of this paper. The authors report no other conflicts of interest in this work.

\section{References}

1. Gradman AH, Basile JN, Carter BL, Bakris GL; American Society of Hypertension Writing Group. Combination therapy in hypertension. J Clin Hypertens (Greenwich). 2011;13:146-154.

2. Danon-Hersch N, Marques-Vidal P, Bovet P, et al. Prevalence, awareness, treatment and control of high blood pressure in a Swiss city general population: the CoLaus study. Eur J Cardiovasc Prev Rehabil. 2009;16: 66-72.

3. Mancia G, Fagard R, Narkiewicz K, et al. 2013 ESH/ESC guidelines for the management of arterial hypertension: the Task Force for the Management of Arterial Hypertension of the European Society of Hypertension (ESH) and of the European Society of Cardiology (ESC). Eur Heart J. 2013;34:2159-2219.

4. de la Sierra A, Barrios V. Blood pressure control with angiotensin receptor blocker-based three-drug combinations: key trials. Adv Ther. 2012;29:401-415.
5. Wald DS, Law M, Morris JK, Bestwick JP, Wald NJ. Combination therapy versus monotherapy in reducing blood pressure: metaanalysis on 11,000 participants from 42 trials. Am J Med. 2009;122: 290-300.

6. Guidelines of the Swiss Society of Hypertension. 2009. Available from: http://www.swisshypertension.ch/guidelines.htm. Accessed August 11, 2014.

7. Chobanian AV, Bakris GL, Black HR, et al. The Seventh Report of the Joint National Committee on Prevention, Detection, Evaluation, and Treatment of High Blood Pressure: the JNC 7 report. JAMA. 2003;289:2560-2572

8. Go AS, Bauman MA, Coleman King SM, et al. An effective approach to high blood pressure control: a science advisory From the American Heart Association, the American College of Cardiology, and the Centers for Disease Control and Prevention. Hypertension. 2014;63:878-885.

9. Brixner DI, Jackson KC 2nd, Sheng X, Nelson RE, Keskinaslan A Assessment of adherence, persistence, and costs among valsartan and hydrochlorothiazide retrospective cohorts in free-and fixed-dose combinations. Curr Med Res Opin. 2008;24:2597-2607.

10. Bangalore S, Shahane A, Parkar S, Messerli FH. Compliance and fixeddose combination therapy. Curr Hypertens Rep. 2007;9:184-189.

11. Gupta AK, Arshad S, Poulter NR. Compliance, safety, and effectiveness of fixed-dose combinations of antihypertensive agents: a meta-analysis. Hypertension. 2010;55:399-407.

12. Breitscheidel L, Ehlken B, Kostev K, Oberdiek MS, Sandberg A, Schmieder RE. Real-life treatment patterns, compliance, persistence, and medication costs in patients with hypertension in Germany. $J$ Med Econ. 2012;15:155-165

13. Schafer HH, Scheunert U. Costs of current antihypertensive therapy in Switzerland: an economic evaluation of 3,489 patients in primary care. Swiss Med Wkly. 2013;143:w13854.

14. Schafer HH, Sudano I, Theus GR, Noll G, Burnier M. Target blood pressure attainment with antihypertensive therapy in Swiss primary care. Blood Press. 2012;21:211-219.

15. Feldman RD, Zou GY, Vandervoort MK, Wong CJ, Nelson SA, Feagan BG. A simplified approach to the treatment of uncomplicated hypertension: a cluster randomized, controlled trial. Hypertension. 2009;53:646-653.

16. Neutel JM. Prescribing patterns in hypertension: the emerging role of fixed-dose combinations for attaining BP goals in hypertensive patients. Curr Med Res Opin. 2008;24:2389-2401.

17. Bundesamt für Statistik (Hrsg.): Gesundheit und Gesundheitsverhalten in der Schweiz 2007 - Schweizerische Gesundheitsbefragung. BFS Neuchâtel. 2010.

18. Zygmuntowicz M, Owczarek A, Elibol A, Chudek J. Comorbidities and the quality of life in hypertensive patients. Polskie Archiwum Medycyny Wewnetrznej. 2012;122:333-340.

19. Bisognano JD, Townsend KA, Skyles AJ, Samuels KM. Prevalence of comorbidities and their influence on blood pressure goal attainment in geriatric patients. Am J Geriatr Cardiol. 2007;16:24-29.

20. Bronsert MR, Henderson WG, Valuck R, Hosokawa P, Hammermeister K. Comparative effectiveness of antihypertensive therapeutic classes and treatment strategies in the initiation of therapy in primary care patients: a Distributed Ambulatory Research in Therapeutics Network (DARTNet) study. J Am Board Fam Med. 2013;26:529-538.

21. Chobanian AV. Shattuck Lecture. The hypertension paradox - more uncontrolled disease despite improved therapy. $N$ Engl J Med. 2009; 361:878-887.

22. Sherrill B, Halpern M, Khan S, Zhang J, Panjabi S. Single-pill vs freeequivalent combination therapies for hypertension: a meta-analysis of health care costs and adherence. J Clin Hypertens (Greenwich). 2011;13:898-909.

23. Baser O, Andrews LM, Wang L, Xie L. Comparison of real-world adherence, healthcare resource utilization and costs for newly initiated valsartan/amlodipine single-pill combination versus angiotensin receptor blocker/calcium channel blocker free-combination therapy. J Med Econ. 2011;14:576-583. 
24. Belsey JD. Optimizing adherence in hypertension: a comparison of outcomes and costs using single tablet regimens vs individual component regimens. J Med Econ. 2012;15:897-905.

25. Myers MG. Pseudoresistant hypertension attributed to white-coat effect. Hypertension. 2012;59:532-533.

26. Myers MG, Godwin M, Dawes M, et al. Conventional versus automated measurement of blood pressure in primary care patients with systolic hypertension: randomised parallel design controlled trial. BMJ. 2011;342:d286.

27. Kjeldsen SE, Messerli FH, Chiang CE, Meredith PA, Liu L. Are fixeddose combination antihypertensives suitable as first-line therapy? Curr Med Res Opin. 2012;28:1685-1697.

28. Neuhauser H, Thamm M, Ellert U. [Blood pressure in Germany 20082011: results of the German Health Interview and Examination Survey for Adults (DEGS1)]. Bundesgesundheitsblatt Gesundheitsforschung Gesundheitsschutz. 2013;56:795-801.

29. Oliveras A, Schmieder RE. Clinical situations associated with difficultto-control hypertension. J Hypertens. 2013;31 Suppl 1:S3-S8.

30. Olives C, Myerson R, Mokdad AH, Murray CJ, Lim SS. Prevalence, awareness, treatment, and control of hypertension in United States counties, 2001-2009. PLoS One. 2013;8:e60308.

31. Flack JM, Calhoun DA, Satlin L, Barbier M, Hilkert R, Brunel P. Efficacy and safety of initial combination therapy with amlodipine/ valsartan compared with amlodipine monotherapy in black patients with stage 2 hypertension: the EX-STAND study. J Hum Hypertens. 2009;23:479-489.
32. Kalra S, Kalra B, Agrawal N. Combination therapy in hypertension: an update. Diabetol Metab Syndr. 2010;2:44.

33. Mancia G, Schumacher H, Redon J, et al. Blood pressure targets recommended by guidelines and incidence of cardiovascular and renal events in the Ongoing Telmisartan Alone and in Combination With Ramipril Global Endpoint Trial (ONTARGET). Circulation. 2011;124: 1727-1736.

34. Dahlof B, Devereux RB, Kjeldsen SE, et al. Cardiovascular morbidity and mortality in the Losartan Intervention For Endpoint reduction in hypertension study (LIFE): a randomised trial against atenolol. Lancet. 2002;359:995-1003.

35. Dahlof B, Sever PS, Poulter NR, et al. Prevention of cardiovascular events with an antihypertensive regimen of amlodipine adding perindopril as required versus atenolol adding bendroflumethiazide as required, in the Anglo-Scandinavian Cardiac Outcomes Trial-Blood Pressure Lowering Arm (ASCOT-BPLA): a multicentre randomised controlled trial. Lancet. 2005;366:895-906.

36. Jamerson K, Devereux R, Bakris GL, et al. Benazepril plus amlodipine or hydrochlorothiazide for hypertension in high-risk patients. $N$ Engl J Med. 2008;359:2417-2428.

37. Salvetti A, Ghiadoni L. Thiazide diuretics in the treatment of hypertension: an update. J Am Soc Nephrol. 2006;17:S25-S29.

38. Alderman MH, Cohen H, Madhavan S. Diabetes and cardiovascular events in hypertensive patients. Hypertension. 1999;33:1130-1134.
International Journal of General Medicine

\section{Publish your work in this journal}

The International Journal of General Medicine is an international, peer-reviewed open-access journal that focuses on general and internal medicine, pathogenesis, epidemiology, diagnosis, monitoring and treatment protocols. The journal is characterized by the rapid reporting of reviews, original research and clinical studies across all disease areas.

\section{Dovepress}

A key focus is the elucidation of disease processes and management protocols resulting in improved outcomes for the patient.The manuscript management system is completely online and includes a very quick and fair peer-review system. Visit http://www.dovepress.com/ testimonials.php to read real quotes from published authors. 